\title{
Stock Market Efficiency Analysis using Long Spans of Data: A Multifractal Detrended Fluctuation Approach
}

\author{
Aviral Kumar Tiwari*, Goodness C. Aye ${ }^{* *}$ and Rangan Gupta***
}

\section{Highlights}

- We examined stock market efficiency.

- Longest span of data from 10 countries were used.

- Both short- and long term components of MF-DFA were explored.

- Efficiency varied over time.

- Most markets are efficient in the long term relative to the short term.

\begin{abstract}
This paper investigates the multifractality and efficiency of stock markets in eight developed (Canada, France, Germany, Italy, Japan, Switzerland, UK and USA) and two emerging (India and South Africa) countries for which long span of data, covering over or nearly a century in each case, is available to avoid sample bias. We employ the Multifractal Detrended Fluctuation Analysis (MF-DFA). Our findings show that the stock markets are multifractal and mostly long-term persistent. Most markets are more efficient in the long-term than in the short-term. The findings are robust to small and large fluctuations. We draw the economic implications of these results.
\end{abstract}

Keywords: Stock market, efficiency, short-term, long-term, multifractal detrended fluctuation analysis, Hurst exponent

JEL Classification: C22, G10, G14, G15

\section{Introduction}

The value of most financial assets depreciated during the recent economic and financial crisis of 2007-2008. Therefore, investors need to make asset allocation decisions that lead to high returns while reducing risk (Aye et al., 2017, forthcoming). The Efficient Market Hypothesis $(\mathrm{EMH})$ has become an important theoretical device that fosters understanding and promotion of quality financial markets. A market is efficient in the weak-form if all the past information contained in price movements is fully reflected in the current prices (Fama, 1970). In an efficient market, it is not possible to predict prices based on historical price information as prices follow random walk. This makes it difficult for investors to make abnormal profit. In an inefficient market, price signals tend to understate or overstate the impact of new information (Pagan, 1996; Mensi et al, 2017; Ali et al., 2018) thereby affecting efficient resource allocation.

\footnotetext{
* Montpellier Business School, 2300, avenue des Moulins, 34185 Montpellier cedex 4 0002, France. Email: aviral.eco@gmail.com.

** Department of Economics, University of Pretoria, Pretoria, 0002, South Africa. Email: goodness.aye@gmail.com.

*** Corresponding author. Department of Economics, University of Pretoria, Pretoria, 0002, South Africa. Email: rangan.gupta@up.ac.za.
} 
Although large empirical literature exists on stock market efficiency, the results are sometimes mixed or inconclusive (Rizvi et al. 2014; Shynkevich, 2016; Mitra et al., 2017; Ali et al., 2018; Syed and Bajwa, forthcoming). We contribute to the literature on stock market efficiency by deriving the weak-form efficiency rankings in the short- and long-term for eight developed (Canada, France, Germany, Italy, Japan, Switzerland, UK and USA) and two emerging (India and South Africa) countries using the longest available monthly data, covering over or nearly a century. This enables us to capture the entire historical evolution of the stock market dynamics, reduce noise and eliminate possible sample bias. We use the multifractal detrended fluctuation analysis (MF-DFA) proposed by Kantelhardt et al. (2002) that presents a flexible and efficient way of testing the multifractal (long memory) properties of a non-stationary time series (Mensi et al., 2017; Bouoiyour, et al., forthcoming). It allows quantifying the multiple scaling exponents within a time series.

The remainder of the paper is organized as follows: the methodology is presented in section 2. Section 3 presents the data and results while section 4 concludes.

\section{Methodology}

The MF-DFA is used to analyse the efficiency of stock markets of eight developed and two emerging countries. Following Kantelhardt et al. (2002), this method consists of five steps:

Let $\{x(i), i=1, \cdots, N\}$ be a time series, where $N$ is the length.

Step 1. Determine the profile

$$
y(i)=\sum_{k=1}^{i}[x(k)-\bar{x}]
$$

where $\bar{x}$ denotes the averaging over the entire time series.

Step 2. The profile $y(i)$ is divided into $N_{s} \equiv \operatorname{int}(N / s)$ non-overlapping segments (windows) of equal length $s$.

Step 3. The local trend is computed for each of the $2 N_{s}$ segments by a least square fit of the series. Thereafter, the variance is obtained:

$$
F^{2}(s, v)=\frac{1}{s} \sum_{i=1}^{s}\left\{Y[(v-1) s+i]-y_{v}(i)\right\}^{2},
$$

For each segment $v, v=1,2, \cdots, N_{s}$ and

$$
F^{2}(s, v)=\frac{1}{s} \sum_{i=1}^{s}\left\{Y\left[N-\left(v-N_{s}\right) s+i\right]-y_{v}(i)\right\}^{2},
$$

for $v=N_{s}+1, \cdots, 2 N_{S}$.

Here, $y_{v}(i)$ is the fitting polynomial in segment $v$.

Step 4. The $q$ th order fluctuation function $F_{q}(\mathrm{~s})$ is obtained by averaging over all segments (subsets):

$$
F_{q}(\mathrm{~s})=\left\{\frac{1}{2 N_{s}} \sum_{v=1}^{2 N_{s}}\left[F^{2}(s, v)\right]^{q / 2}\right\}^{1 / q} .
$$


The index variable $q$ can take any real value except zero. For $q=0$, the value $h(0)$ cannot be determined directly because of the diverging exponent. Instead, a logarithmic average procedure has to be employed. For $q=2$, the standard DFA procedure is retrieved.

Step 5. Determine the scaling behaviour of the fluctuation functions by analysing log$\log$ plots of $F_{q}(s)$ versus $s$ for each value of $q$. If the series $x(i)$ are long-range power-law correlated, $F_{q}(s)$ increases for large values of $s$, as a power-law:

$$
F_{q}(s) \sim S^{h(q)} .
$$

In general, the exponent $h(q)$ will depend on $q$. If $h(q)$ does not depend on $q$, the time series is monofractal, otherwise it is multifractal, meaning that the scaling behaviour of small fluctuations $(q<0)$ is different from that of the large variations $(q>0)$.

\section{Data and Results}

We use monthly stock returns data on eight developed (Canada, France, Germany, Italy, Japan, Switzerland, UK and USA) and two emerging (India and South Africa) countries obtained from the Global Financial Database. The data for these countries span the periods of 1915M02-2017M07, 1898M01-2017M07, 1870M01-2017M07, 1905M02-2017M07, 1914M08- 2017M07, 1916M02-2017M07, 1693M02-2017M07 and 1791M09-2017M07, 1920M08-2017M07, and 1910M02-2017M07, respectively. Figure 1 presents the plot of these series. In general, these series look nonlinear, volatile and not normally distributed.
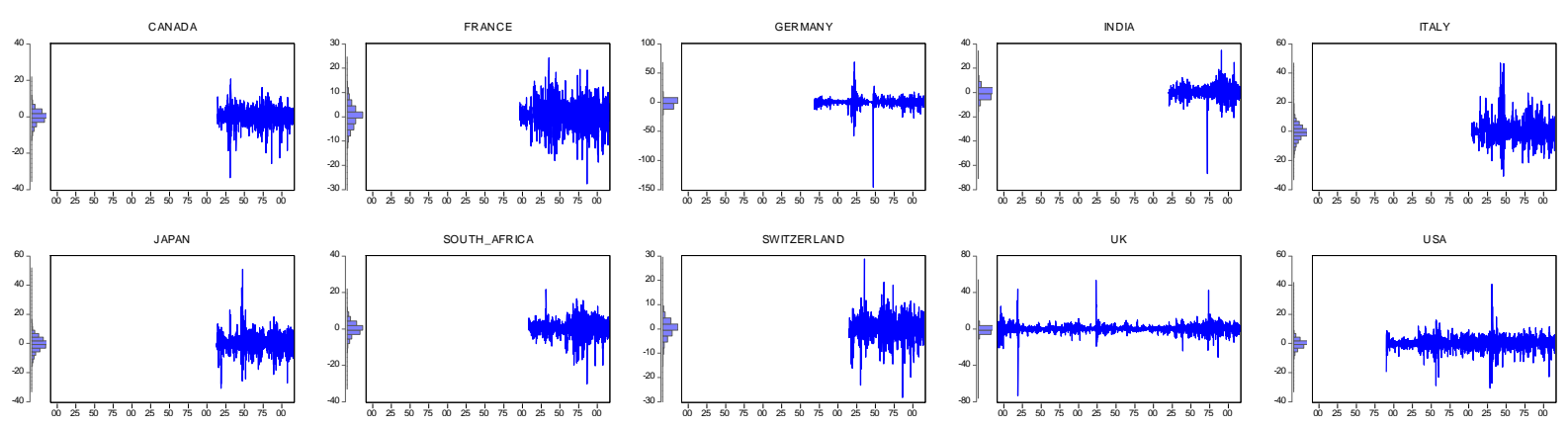

Figure 1: Time plots of Stock Returns with associated histograms

The scaling behaviour of the stock markets is presented in Figures 2 to 11 . The local slope of the plots changes with crossover time scales $\left(\log s^{*}\right) \approx 5$ for all the countries but about 2.5 for France, Germany, India and Italy. Therefore, we applied the MF-DFA technique to two different time scales corresponding to short-term component $\left(s^{*}<s\right)$ and long-term component $\left(s^{*}>s\right)$ of the stock market dynamics. There is evidence of mutifractality as $\mathrm{h}(\mathrm{q})$ varies with changes in (q). Also the multifractal spectra resemble large arcs which contrast those of monofractal time series. 

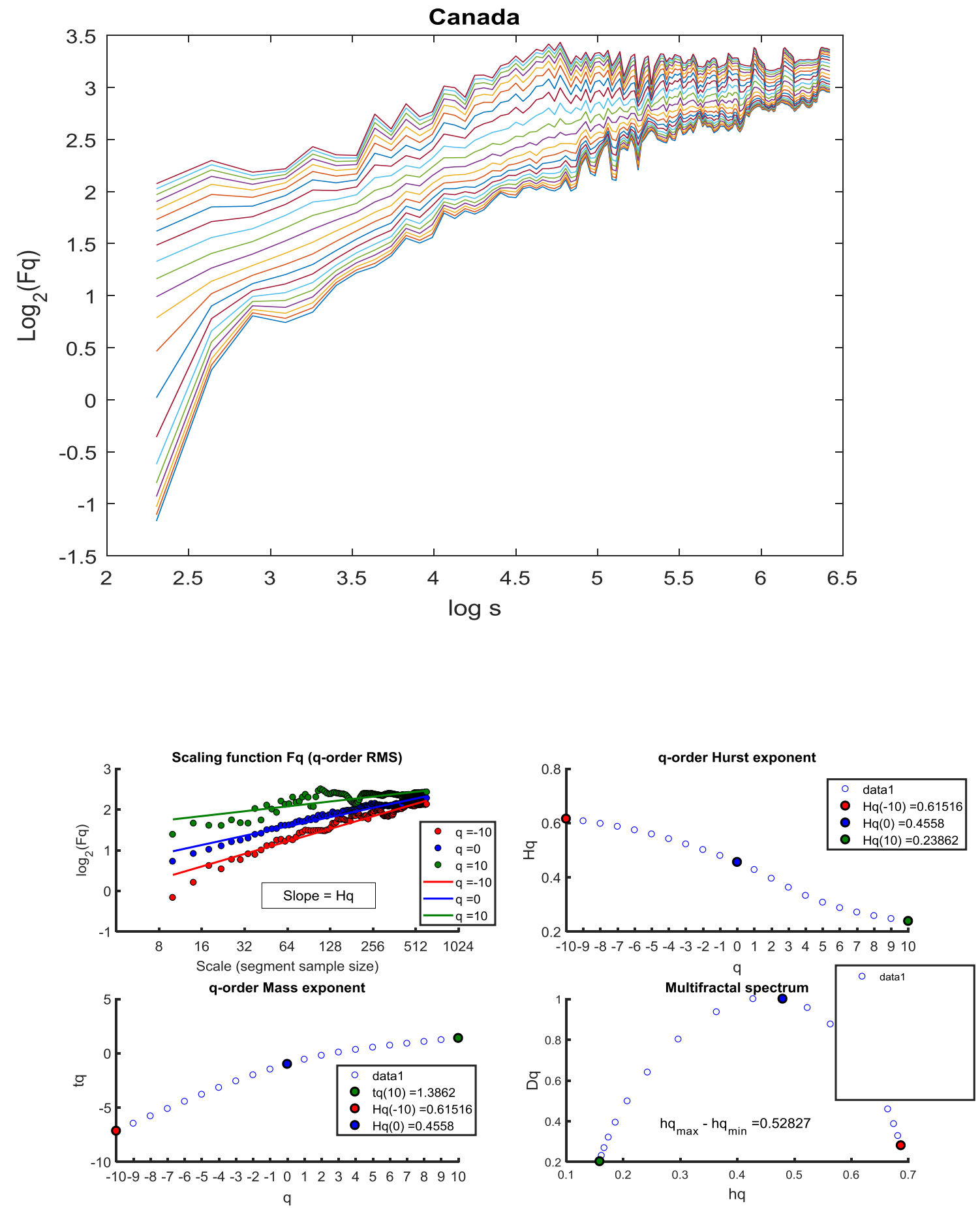

Figure 2: Multifractal behaviour of stock market returns in Canada 

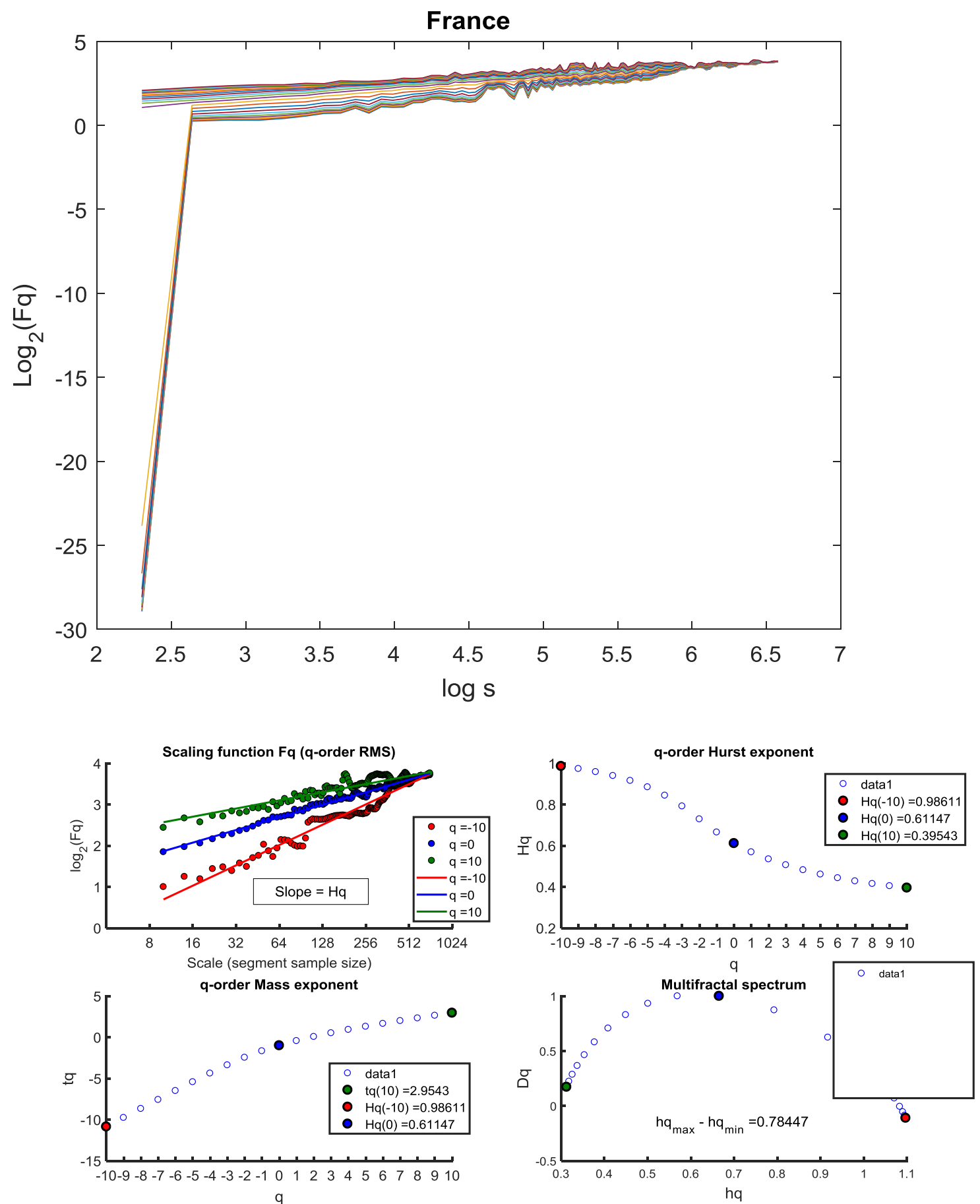

Figure 3: Multifractal behaviour of stock market returns in France 

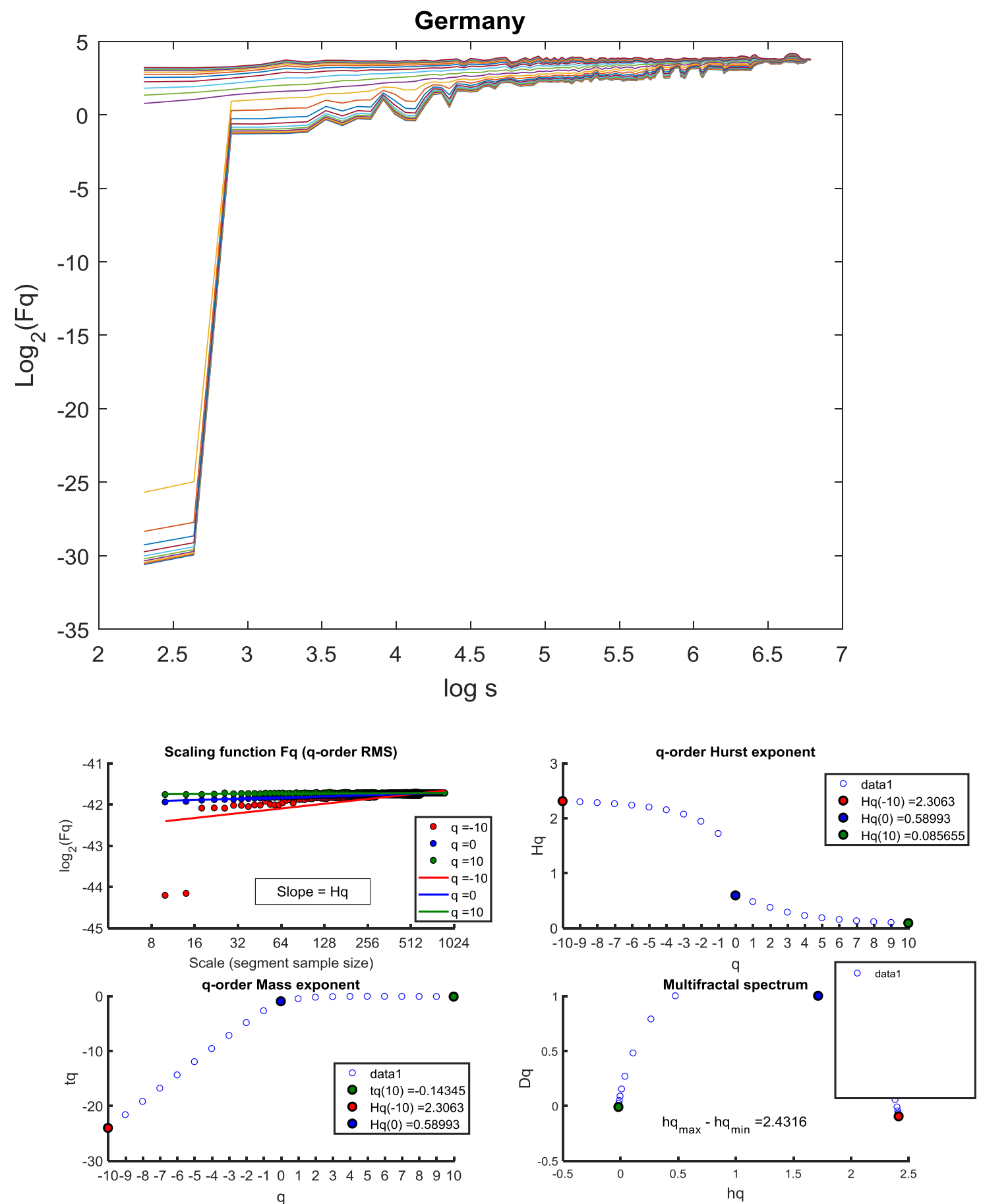

Figure 4: Multifractal behaviour of stock market returns in Germany 

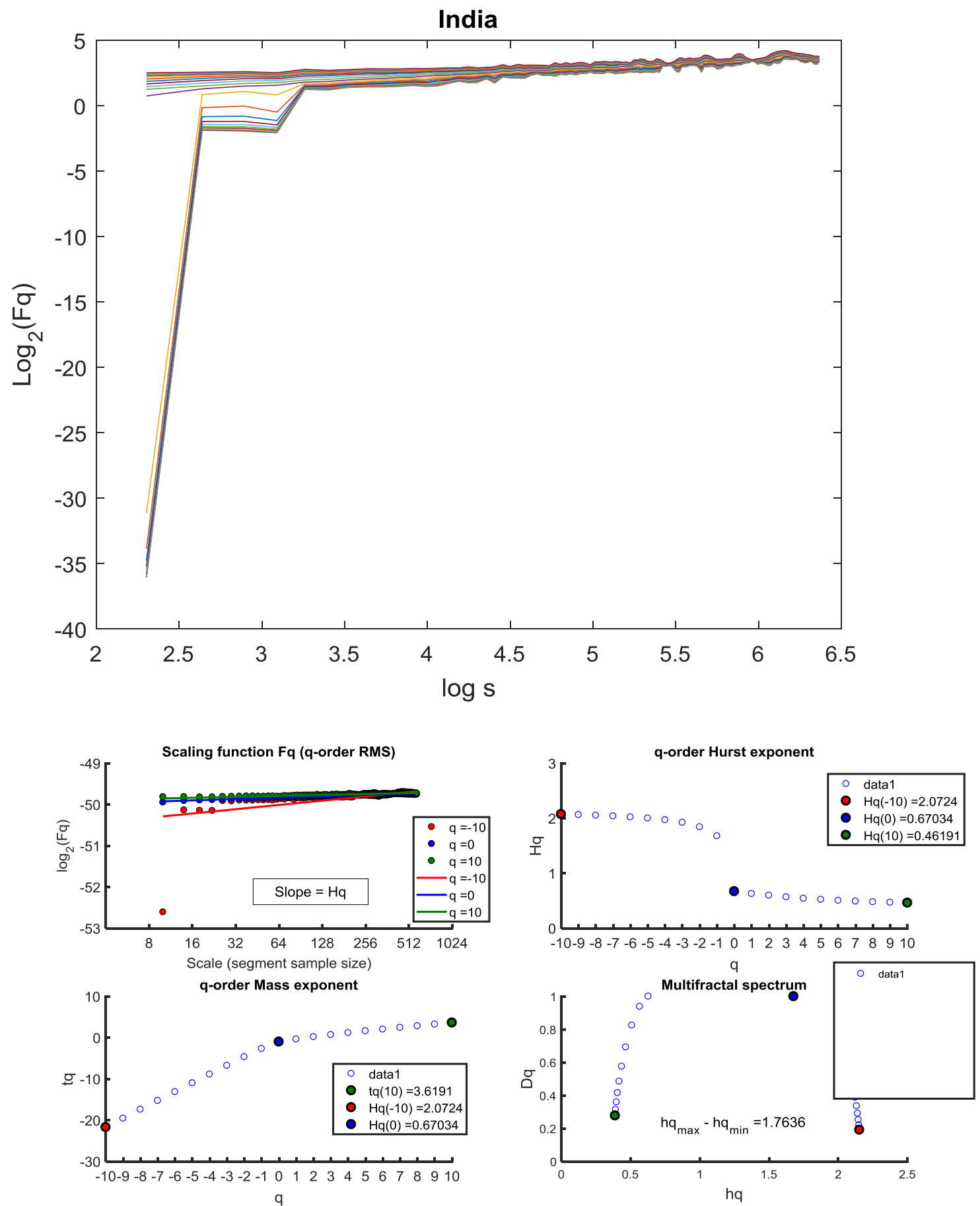

Figure 5: Multifractal behaviour of stock market returns in India 

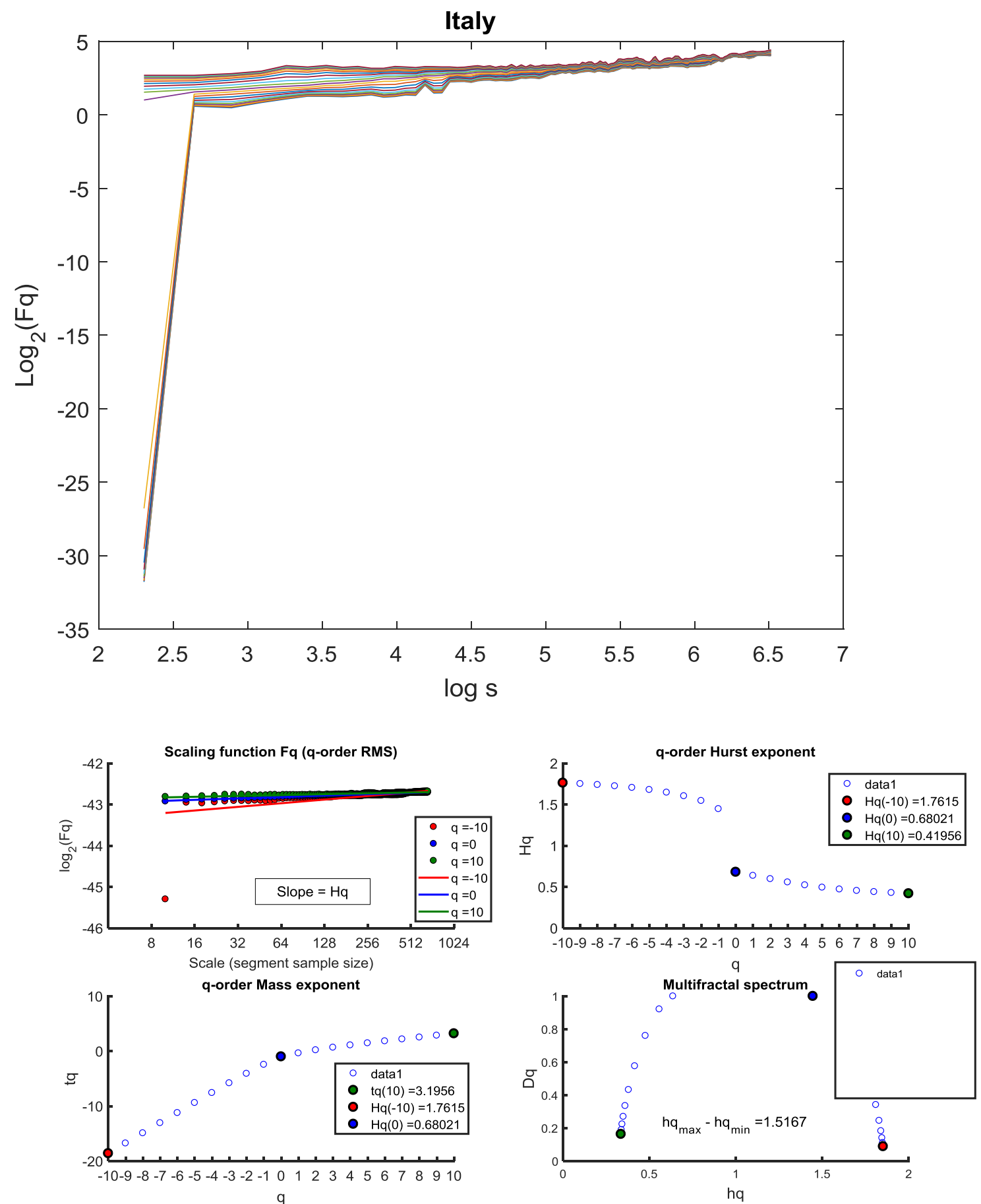

Figure 6: Multifractal behaviour of stock market returns in Italy 

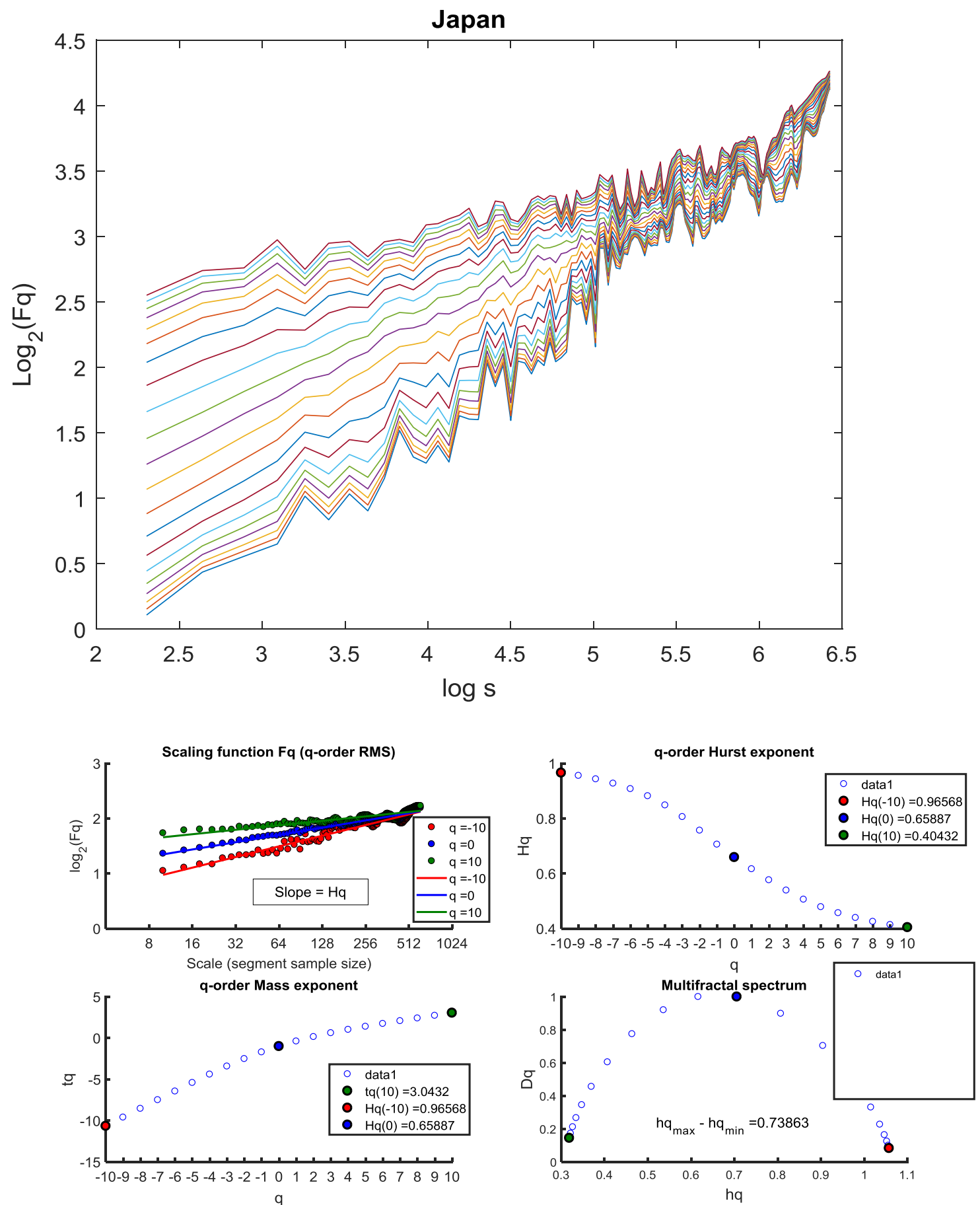

Figure 7: Multifractal behaviour of stock market returns in Japan 

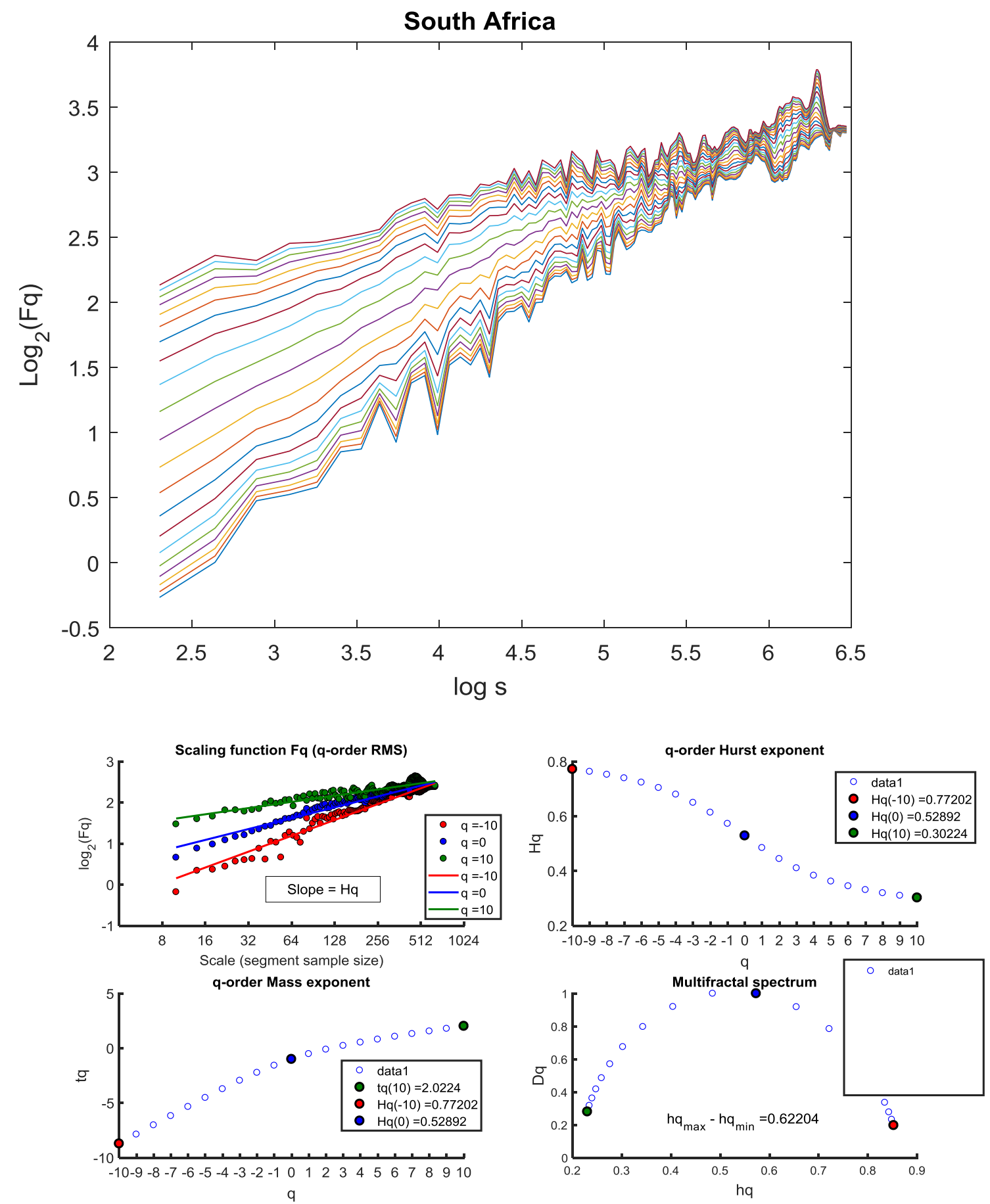

Figure 8: Multifractal behaviour of stock market returns in South Africa 

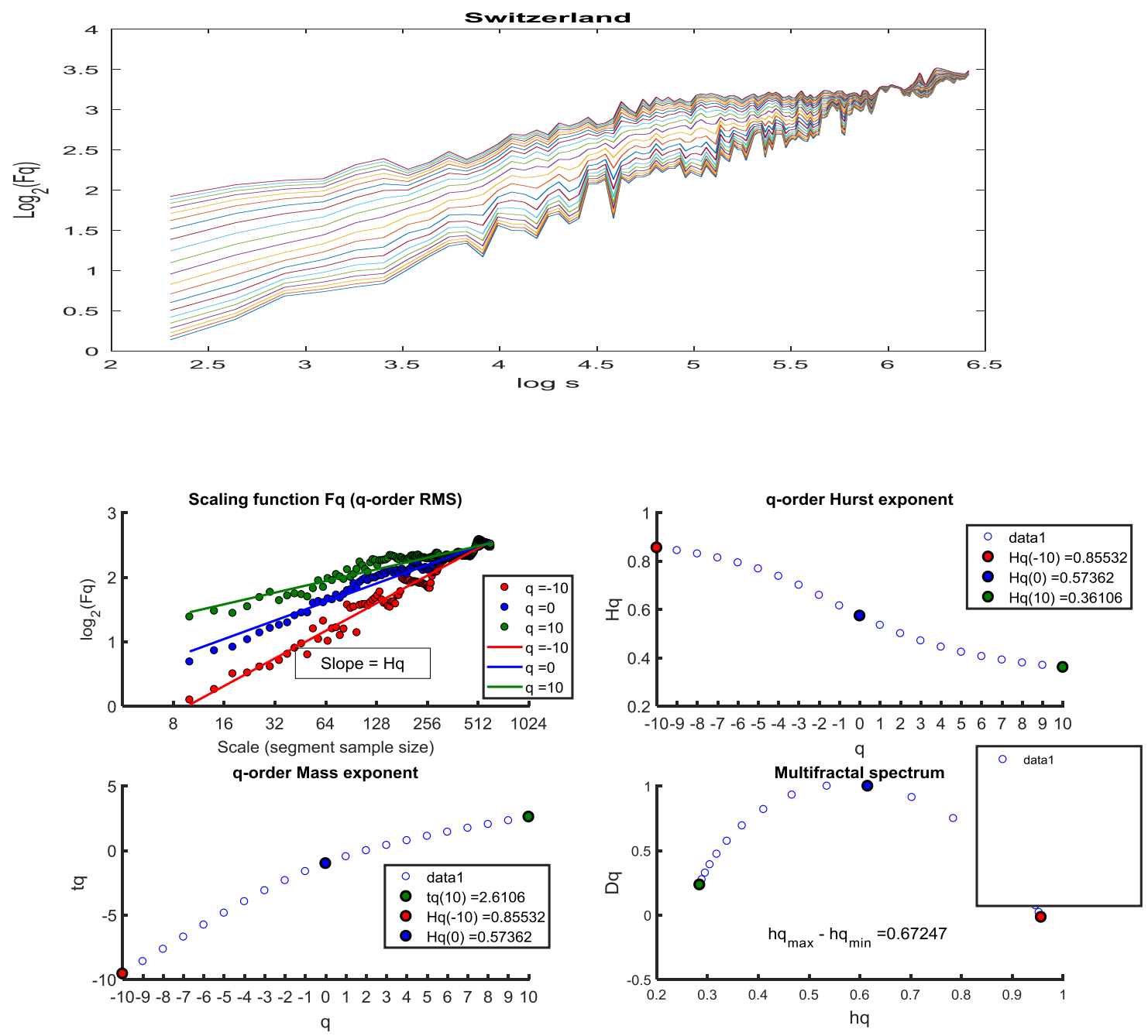

Figure 9: Multifractal behaviour of stock market returns in Switzerland 

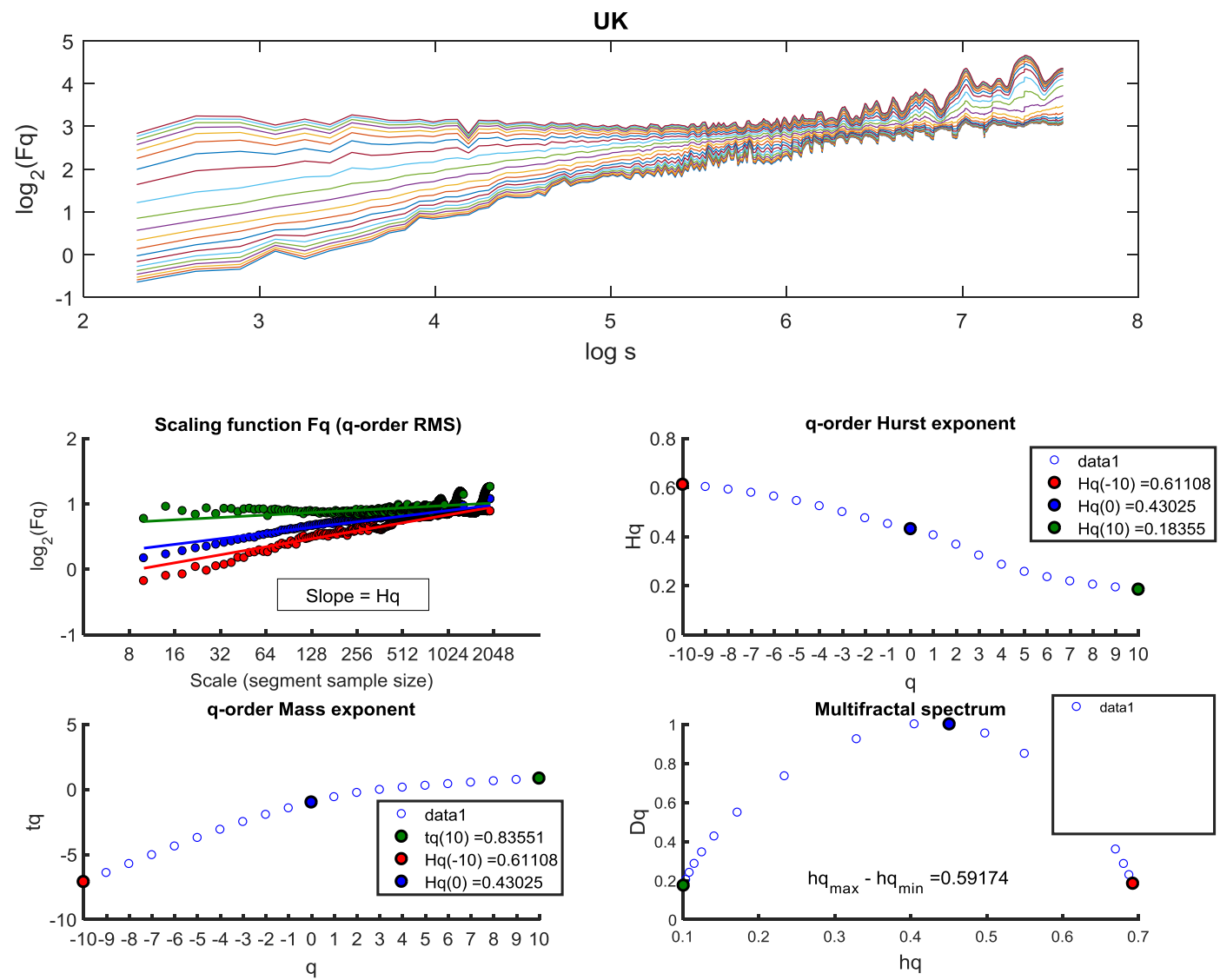

Figure 10: Multifractal behaviour of stock market returns in the UK. 

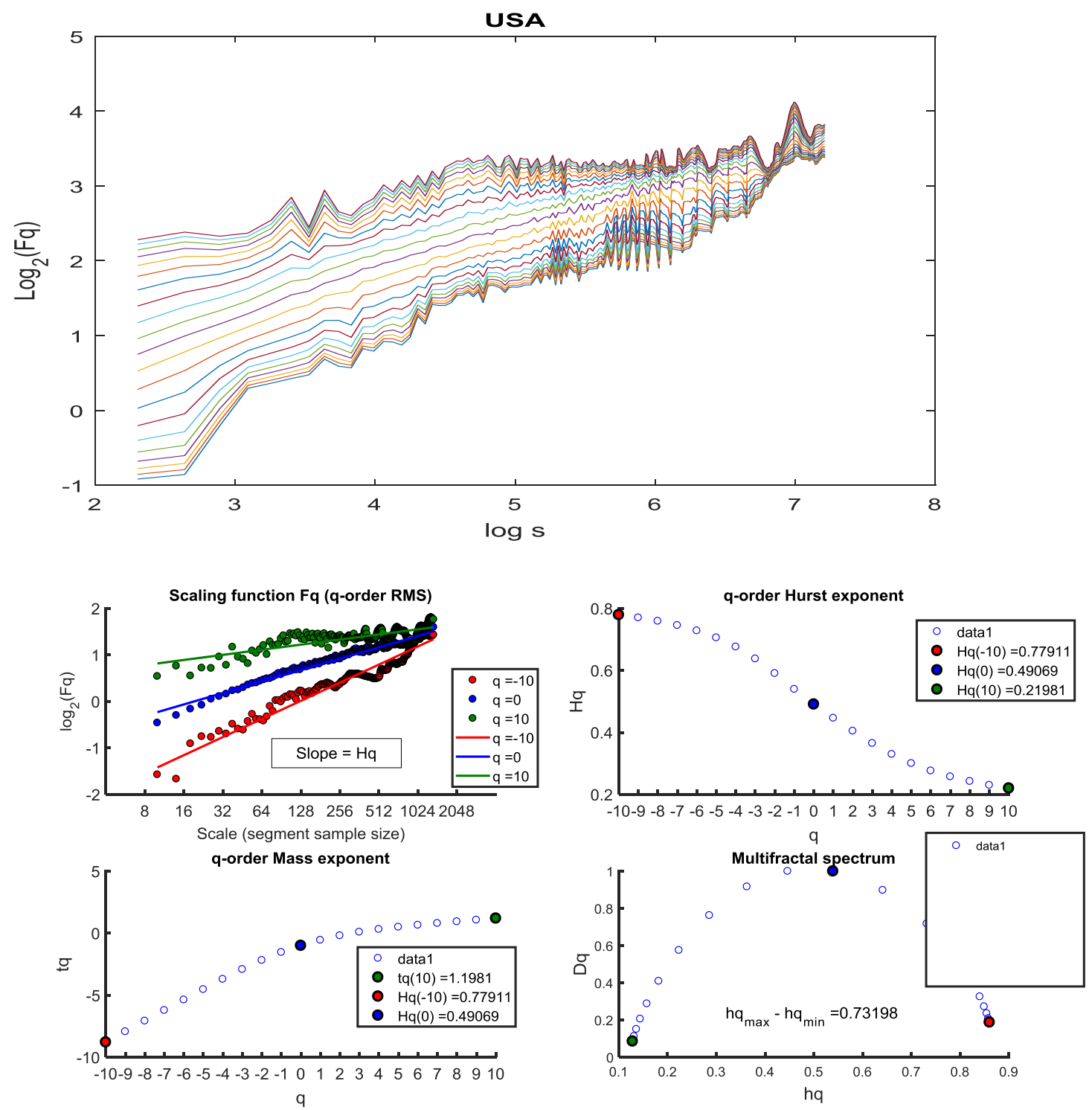

Figure 11: Multifractal behaviour of stock market returns in USA

Table 1 presents the generalized Hurst exponents for short- and long-term. Upper bound for $q$ is 4 and a lower bound is -4 . Hence, $\mathrm{h}(\mathrm{q})$ depicts small (large) fluctuations for $\mathrm{q}<0(\mathrm{q}>0)$. The generalized Hurst exponents vary with the values of q, implying multifractality in the shortrun and long-run. In general, we find stronger evidence of long-term persistent (hq $>0.5)$ which violates the weak-form efficiency. In the case of small fluctuations, all stock returns are persistent in the short- and long-term except Canada and UK which are mean reverting (hq $<0.5$ ) in the long-term. For $\mathrm{q}=2$ corresponding to the standard DFA, all the Hurst exponents are different from 0.5 (deviation from random walk behaviour). In the short-term, all the return series exhibit long memory features. In the long-term, all series also show longterm persistence except Canada, Germany, South Africa, Switzerland and USA that exhibit short-term persistence. 
Table 1: Generalized Hurst exponents of sector returns series for short- and long-term components from q equal to -4 to 4

\begin{tabular}{|c|c|c|c|c|c|c|c|c|c|c|c|c|c|c|c|c|c|c|c|c|}
\hline $\begin{array}{l}\text { Cou- } \\
\text { ntry }\end{array}$ & \multicolumn{2}{|c|}{ UK } & \multicolumn{2}{|c|}{ Canada } & \multicolumn{2}{|c|}{ France } & \multicolumn{2}{|c|}{ Germany } & \multicolumn{2}{|c|}{ India } & \multicolumn{2}{|c|}{ South Africa } & \multicolumn{2}{|c|}{ Switzerland } & \multicolumn{2}{|c|}{ Japan } & \multicolumn{2}{|c|}{ Italy } & \multicolumn{2}{|c|}{ USA } \\
\hline$q$ & $\begin{array}{l}\text { Short- } \\
\text { Term }\end{array}$ & $\begin{array}{l}\text { Long- } \\
\text { Term }\end{array}$ & $\begin{array}{l}\text { Short- } \\
\text { Term }\end{array}$ & $\begin{array}{l}\text { Long- } \\
\text { Term }\end{array}$ & $\begin{array}{l}\text { Short- } \\
\text { Term }\end{array}$ & $\begin{array}{l}\text { Long- } \\
\text { Term }\end{array}$ & $\begin{array}{l}\text { Short- } \\
\text { Term }\end{array}$ & $\begin{array}{l}\text { Long- } \\
\text { Term }\end{array}$ & $\begin{array}{l}\text { Short- } \\
\text { Term }\end{array}$ & $\begin{array}{l}\text { Long- } \\
\text { Term }\end{array}$ & $\begin{array}{l}\text { Short- } \\
\text { Term }\end{array}$ & $\begin{array}{l}\text { Long- } \\
\text { Term }\end{array}$ & $\begin{array}{l}\text { Short- } \\
\text { Term }\end{array}$ & $\begin{array}{l}\text { Long- } \\
\text { Term }\end{array}$ & $\begin{array}{l}\text { Short- } \\
\text { Term }\end{array}$ & $\begin{array}{l}\text { Long- } \\
\text { Term }\end{array}$ & $\begin{array}{l}\text { Short- } \\
\text { Term }\end{array}$ & $\begin{array}{l}\text { Long- } \\
\text { Term }\end{array}$ & $\begin{array}{l}\text { Short- } \\
\text { Term }\end{array}$ & $\begin{array}{l}\text { Long- } \\
\text { Term }\end{array}$ \\
\hline-4 & 0.778 & 0.469 & 1.083 & 0.425 & 10.247 & 0.885 & 17.310 & 0.830 & 13.844 & 0.702 & 0.841 & 0.621 & 0.733 & 0.675 & 0.707 & 0.822 & 11.290 & 0.806 & 0.858 & 0.708 \\
\hline-3 & 0.756 & 0.455 & 0.964 & 0.407 & 10.145 & 0.819 & 17.171 & 0.779 & 13.582 & 0.684 & 0.817 & 0.588 & 0.732 & 0.632 & 0.709 & 0.788 & 11.190 & 0.776 & 0.796 & 0.665 \\
\hline-2 & 0.734 & 0.447 & 0.825 & 0.387 & 9.899 & 0.740 & 16.834 & 0.705 & 13.027 & 0.665 & 0.787 & 0.550 & 0.730 & 0.582 & 0.706 & 0.749 & 10.950 & 0.742 & 0.747 & 0.612 \\
\hline-1 & 0.709 & 0.454 & 0.730 & 0.365 & 9.018 & 0.663 & 15.522 & 0.607 & 11.695 & 0.644 & 0.748 & 0.511 & 0.721 & 0.528 & 0.689 & 0.709 & 10.093 & 0.709 & 0.719 & 0.554 \\
\hline 0 & 0.681 & 0.487 & 0.672 & 0.337 & 0.672 & 0.597 & 0.838 & 0.506 & 0.821 & 0.622 & 0.699 & 0.472 & 0.699 & 0.477 & 0.655 & 0.672 & 0.776 & 0.678 & 0.698 & 0.501 \\
\hline 1 & 0.645 & 0.539 & 0.623 & 0.304 & 0.621 & 0.546 & 0.728 & 0.406 & 0.657 & 0.601 & 0.642 & 0.436 & 0.661 & 0.433 & 0.606 & 0.638 & 0.636 & 0.651 & 0.670 & 0.457 \\
\hline 2 & 0.564 & 0.581 & 0.575 & 0.264 & 0.593 & 0.504 & 0.649 & 0.318 & 0.589 & 0.582 & 0.583 & 0.404 & 0.610 & 0.398 & 0.540 & 0.608 & 0.596 & 0.627 & 0.625 & 0.417 \\
\hline 3 & 0.428 & 0.598 & 0.534 & 0.222 & 0.558 & 0.470 & 0.552 & 0.250 & 0.515 & 0.565 & 0.528 & 0.378 & 0.553 & 0.370 & 0.465 & 0.582 & 0.553 & 0.608 & 0.565 & 0.380 \\
\hline 4 & 0.315 & 0.601 & 0.503 & 0.185 & 0.518 & 0.441 & 0.482 & 0.200 & 0.444 & 0.550 & 0.484 & 0.357 & 0.500 & 0.348 & 0.399 & 0.559 & 0.512 & 0.592 & 0.502 & 0.348 \\
\hline
\end{tabular}


The market deficiency measure $(M D M)$ used for efficiency rankings are presented in Table 2. The value for an efficient market is zero while it is high for a less efficient market (Mensi et al., 2017). The efficiency of all stock markets change over time. The markets are less efficient in the short- term than in the long-term except for Switzerland and Japan. In the short-term, the most efficient market is Switzerland while the most inefficient market is Germany. In the long-term, Germany is still the most inefficient while UK is the most efficient market. Overall, the findings imply that investors in these markets can predict the stock returns and earn abnormal profit.

Table 2: Ranking of MF-DFA in short- and long-term

\begin{tabular}{|r|l|c|r|l|r|}
\hline & Short-term & & Long-term & \\
\hline Order & Country & Value & Order & Country & Value \\
\hline 1 & Switzerland & 0.1165 & 1 & UK & 0.0658 \\
\hline 2 & Japan & 0.1541 & 2 & India & 0.1260 \\
\hline 3 & South Africa & 0.1788 & 3 & South Africa & 0.1316 \\
\hline 4 & USA & 0.1800 & 4 & Switzerland & 0.1635 \\
\hline 5 & UK & 0.2318 & 5 & USA & 0.1802 \\
\hline 6 & Canada & 0.2929 & 6 & Japan & 0.1905 \\
\hline 7 & France & 4.8827 & 7 & Canada & 0.1953 \\
\hline 8 & Italy & 5.4014 & 8 & Italy & 0.1988 \\
\hline 9 & India & 6.6996 & 9 & France & 0.2221 \\
\hline 10 & Germany & 8.4136 & 10 & Germany & 0.3151 \\
\hline
\end{tabular}

\section{Conclusion}

This paper examines the multifractality and efficiency of stock markets in 10 countries using the MF-DFA approach. Our findings show that the stock markets are multifractal and efficiency varies over time. Most markets are more efficient in the long-term than in the short-term. These findings have important implications for corporate managers, investors, policy makers, regulators and researchers. An inefficient market presents arbitrage opportunities for investors to make abnormal profit. The level of efficiency may be improved through increasing information flow, better trading technology, more active investment strategies and good regulatory institutions. This will ensure that firms receive a fair value for their securities and investors earn risk-adjusted returns. Appropriate portfolio allocation, risk diversification and hedging become possible leading to more economic development. Researchers should incorporate the multifractality features when forecasting stock volatility and crashes. Future research may identify the determinants of efficiency in these markets.

\section{References}

Ali, S., Shahzad, S.J.H., Raza, N., Al-Yahyaee, K.H. (2018) Stock market efficiency: A comparative analysis of Islamic and conventional stock markets. Physica, A 503,139-153.

Aye, G.C., Gil-Alana, L.A., Gupta, R. and Wohar, M E. (2017) The efficiency of the art market: Evidence from variance ratio tests, linear and nonlinear fractional integration approaches. International Review of Economics and Finance, 51(91), 283-294. 
Aye, G.C., Chang, T., Chen, W-Y., Gupta, R. and Wohar, M.E. (forthcoming) Testing the Efficiency of the Art Market using Quantile-Based Unit Root Tests with Sharp and Smooth Breaks. The Manchester School.

Bouoiyour, J., Selmi, R. and Wohar, M.E. (forthcoming) Are Islamic stock markets efficient? A multifractal detrended fluctuation analysis. Finance Research Letters.

Fama, E.F. (1970) Efficient capital markets: A review of theory and empirical work. J. Finance 25 (2), 383-417.

Kantelhardt, J.W., Zschiegner, S.A., Koscielny-Bunde, E., Havlin, S., Bunde, A. and Stanley, H.E. (2002), Multifractal detrended fluctuation analysis of nonstationary time series, Physica A, $31687-114$.

Mensi, W., Tiwari, A.K., and Yoone, S-M. (2017) Global financial crisis and weak-form efficiency of Islamic sectoral stock markets: An MF-DFA analysis. Physica A 471, 135-146.

Mitra, S.K., Chattopadhyay, M., Charan, P. and Bawa, J. (2017) Identifying periods of market inefficiency for return predictability. Applied Economics Letters, 24(10), 668-671.

Rizvi, S.A.R., Dewandaru, G., Bacha, O.I. and Masih, M. (2014) An analysis of stock market efficiency: Developed vs Islamic stock markets using MF-DFA. Physica A, 407 86-99.

Shynkevich, A. (2016), Predictability of equity returns during a financial crisis. Applied Economics Letters, 23(17), 1201-1205.

Syed, A.M. and Bajwa, I.A. (forthcoming) Earnings announcements, stock price reaction and market efficiency-the case of Saudi Arabia. International Journal of Islamic and Middle Eastern Finance and Management. 


\section{Supplementary material}

Table A1. Stock market crashes and bear markets

\section{Country}

Canada:

France:

Itabt crisis 27 April 2010

Japanese asset price bubble of 1991; October 27, 1997, global mini-crash; Economic effects
Japan: arising from the September 11 attacks; Stock market downturn of 20029 Oct 2002; Global financial crisis of 2007-2009

October 27, 1997, global mini-crash; Economic effects arising from the September 11 attacks;

Switzerland: Stock market downturn of 9 Oct 2002; Global financial crisis of 2007-2009; European sovereign debt crisis 27 April 201016 Sep 1992; October 27, 1997, global mini-crash; Economic effects arising from the September 11 attacks, Global financial crisis of 2007-2009

South Sea Bubble of 1720; Bengal Bubble of 1769; Credit crisis of 1772; Panic of 1796-97;

UK: $\quad$ Panic of 1825; Panic of 1847; Panic of 1866; Panic of 1873; 1973-74 stock market crash; Black Wednesday

Credit crisis of 1772; Financial Crisis of 1791-92; Panic of 1796-97; Panic of 1819; Panic of 10 May 1837; Panic of 1857; Black Friday 24 Sep 1869; Panic of 1873; Panic of 1893; Panic of 1896; Panic of 17 May 1901; Panic of Oct 1907; Wall Street Crash of 24 Oct 1929; Recession of 1937-38; Kennedy Slide (Flash crash) of 28 May 1962; Black Monday 19 Oct 1987; Friday the

USA: $\quad$ 13th Oct 1989 mini-crash; Early 1990 s recession July 1990 caused by Iraq invasion of Kuwait; October 27, 1997, global mini-crash; Dot-com bubble of 10 March 2000; Stock market downturn of 9 Oct 2002; United States bear market of 11 Oct 2007-2009; Financial crisis of 2007-08 16 Sep 2008 culminating into Global financial crisis of 2007-2009; 2010 Flash Crash 6 May 2010; August 2011 stock markets fall 1 Aug 2011; 2015-16 stock market selloff

October 27, 1997, global mini-crash; Economic effects arising from the September 11 attacks;

India: Ketan Parekh's technology stocks scam of 1999-2001; Stock market downturn of 9 Oct 2002; Global financial crisis of 2007-2009

South October 27, 1997, global mini-crash; Economic effects arising from the September 11 attacks;

Africa: Global financial crisis of 2007-2009 